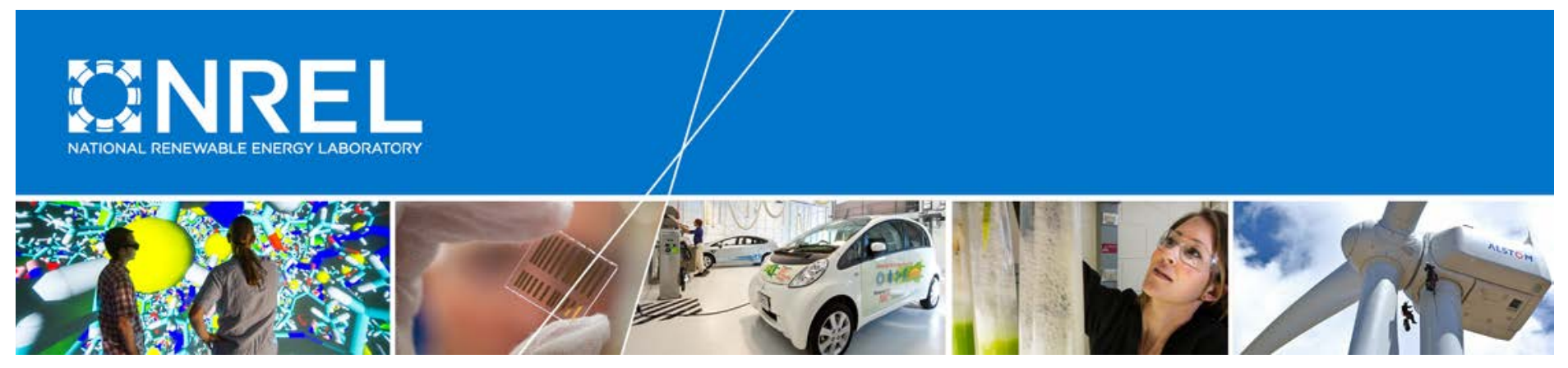

\title{
Cooling Tower \\ (Evaporative Cooling System) Measurement and Verification Protocol
}

Brian Boyd and Kate McMordie Stoughton Pacific Northwest National Laboratory

Taylor Lewis

Colorado Energy Office

NREL Technical Monitor: Charles Kurnik

NREL is a national laboratory of the U.S. Department of Energy Office of Energy Efficiency \& Renewable Energy Operated by the Alliance for Sustainable Energy, LLC

This report is available at no cost from the National Renewable Energy Laboratory (NREL) at www.nrel.gov/publications.

Subcontract Report

NREL/SR-7A40-70219

December 2017

Contract No. DE-AC36-08GO28308 


\section{Cooling Tower (Evaporative Cooling System) Measurement and Verification Protocol}

Brian Boyd and Kate McMordie Stoughton Pacific Northwest National Laboratory

Taylor Lewis

Colorado Energy Office

NREL Technical Monitor: Charles Kurnik

Prepared under Subcontract No. TSA-17-898/285 1392
NREL is a national laboratory of the U.S. Department of Energy Office of Energy Efficiency \& Renewable Energy Operated by the Alliance for Sustainable Energy, LLC

This report is available at no cost from the National Renewable Energy Laboratory (NREL) at www.nrel.gov/publications.

\section{Subcontract Report}

NREL/SR-7A40-70219

December 2017

Contract No. DE-AC36-08GO28308
National Renewable Energy Laboratory 15013 Denver West Parkway

Golden, CO 80401

303-275-3000 • www.nrel.gov 


\title{
This publication was reproduced from the best available copy submitted by the subcontractor and received no editorial review at NREL.
}

\begin{abstract}
NOTICE
This report was prepared as an account of work sponsored by an agency of the United States government. Neither the United States government nor any agency thereof, nor any of their employees, makes any warranty, express or implied, or assumes any legal liability or responsibility for the accuracy, completeness, or usefulness of any information, apparatus, product, or process disclosed, or represents that its use would not infringe privately owned rights. Reference herein to any specific commercial product, process, or service by trade name, trademark, manufacturer, or otherwise does not necessarily constitute or imply its endorsement, recommendation, or favoring by the United States government or any agency thereof. The views and opinions of authors expressed herein do not necessarily state or reflect those of the United States government or any agency thereof.
\end{abstract}

This report is available at no cost from the National Renewable Energy Laboratory (NREL) at www.nrel.gov/publications.

Available electronically at SciTech Connect http:/www.osti.gov/scitech

Available for a processing fee to U.S. Department of Energy and its contractors, in paper, from:

\author{
U.S. Department of Energy \\ Office of Scientific and Technical Information \\ P.O. Box 62 \\ Oak Ridge, TN 37831-0062 \\ OSTI http://www.osti.gov \\ Phone: 865.576.8401 \\ Fax: 865.576.5728 \\ Email: reports@osti.gov
}

Available for sale to the public, in paper, from:

\author{
U.S. Department of Commerce \\ National Technical Information Service \\ 5301 Shawnee Road \\ Alexandria, VA 22312 \\ NTIS http://www.ntis.gov \\ Phone: 800.553 .6847 or 703.605 .6000 \\ Fax: 703.605.6900 \\ Email: orders@ntis.gov
}




\section{Cooling Tower (Evaporative Cooling System) Measurement and Verification Protocol}

Guidelines for Energy Service Companies and Water Efficiency Service Companies to Determine Water Savings of Cooling Tower Efficiency Measures for Use in Performance Contracts

\section{August 2017}

BK Boyd

KL McMordie Stoughton

T Lewis, PE

Prepared by Pacific Northwest National Laboratory and Western Resource Advocates as model guidelines for the State Performance Contracting Programs of Colorado, Nevada, and New Mexico. 


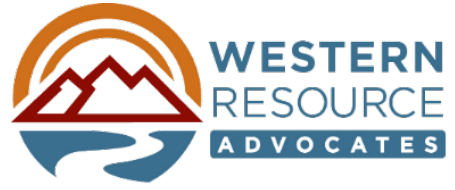

PROTECTING THE WEST'S LAND, AIR \& WATER

\section{Pacific Northwest}

NATIONAL LABORATORY

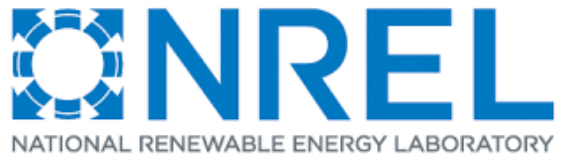

Western Resource Advocates has spent more than 25 years protecting the West's land, air, and water. We use law, science, and economics to craft innovative solutions to the most pressing conservation issues in the region.

The Pacific Northwest National Laboratory's mission is to transform the world through courageous discovery and innovation. For more than 50 years, PNNL has advanced the frontiers of science and engineering in the service of the nation and the world, translating discoveries into tools and technologies in science, energy, the environment, and national security.

The National Renewable Energy Laboratory focuses on creative answers to today's energy challenges. From breakthroughs in fundamental science, to new clean technologies, to integrated energy systems that power our lives, NREL researchers are transforming the way the nation and the world use energy. 


\section{Cooling Tower Measurement and Verification Technical Advisory Group}

Andrew Landfather

Bill Hoffman

Kent Sovocool

Mark R. Gentili

Mike Mendenhall

Niffy Ovuworie

Philip Neff

Richard Chapman

Scott Winter

Thomas Pape

Technical Lead

Brian Boyd

Project Co-Leads

Jorge Figueroa

Taylor Lewis, PE

\section{Senior Advisors}

Chuck Kurnik

Linda Smith

Amelia Nuding
Measurement \& Verification Engineer, Ameresco

President, H.W. (Bill) Hoffman \& Associates

Senior Conservation Research Analyst, Southern Nevada Water Authority

Water Conservation Supervisor, Los Angeles Department of Water and Power Senior Project Developer, Trane

M\&V Program Manager for the Rocky Mountain Region, McKinstry

Engineering Manager, Honeywell Energy Services Group of North America

President, Smart Use, LLC

Lead Water Conservation Specialist, Colorado Springs Utilities

Principal, Best Management Partners

Research Engineer, Pacific Northwest National Laboratory

Senior Water Policy Analyst, Western Resource Advocates

Program Engineer, Colorado Energy Office

Engineer and Project Manager, National Renewable Energy Laboratory President, 9Kft Strategies in Energy

Senior Water Resources Analyst, Western Resource Advocates 


\title{
Steering Committee Members
}

Water, Measurement and Verification (M\&V) Guidelines, and State Performance Contracts Project

\author{
Donald Gilligan President, National Association of Energy Service Companies \\ Mary Ann Dickinson President and CEO, Alliance for Water Efficiency \\ John Canfield President, Trident Energy Services \\ Chris Halpin President, Celtic Energy \\ Patrick Watson Conservation Services Administrator, Southern Nevada Water Authority \\ Carlos Bustos Water Conservation Program Manager, Albuquerque Bernalillo County Water Utility Authority \\ Frank Kinder \\ Senior Conservation Specialist, Colorado Springs Utilities \\ Paul Matuska \\ Manager, Water Accounting and Verification Group, U.S. Bureau of Reclamation \\ William D. Taylor \\ Private Sector Co-Chair, Energy Services Coalition-Nevada Chapter \\ Oscar Rangel \\ Private Sector Co-Chair, Energy Services Coalition-Colorado Chapter \\ Scott Griffith \\ Private Sector Co-Chair, Energy Services Coalition-New Mexico Chapter \\ Harold Trujillo \\ Kelly Thomas \\ Chief, New Mexico Energy Technology and Engineering Bureau, New Mexico EPC Program \\ Energy Program Manager, Nevada Governor's Office of Energy, Nevada EPC Program \\ Taylor Lewis, PE \\ Program Engineer, Colorado Energy Office, Colorado EPC Program
}

\section{Acknowledgements}

The authors thank all of the experts who participated in the Cooling Tower Technical Advisory Group; we are grateful for their invaluable time and generous support. We also genuinely appreciate, and are fortunate to have, the excellent and gracious guidance of the Colorado Energy Office, Chuck Kurnik (NREL), Linda Smith (9Kft Strategies in Energy), the project's Steering Committee, and Jim Zarske (Nexant, Inc.; who suggested the use of the Uniform Methods Project approach for this project). The authors take full responsibility for any error found in these guidelines, and the participation of the above-listed entities in the Technical Advisory Group does not imply their agreement with or endorsement of the concepts, analysis, methodologies, or conclusions presented in this document.

This work was funded through a grant from the Rosin Fund - Environment Program. 


\section{Table of Contents}

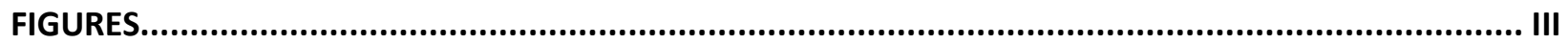

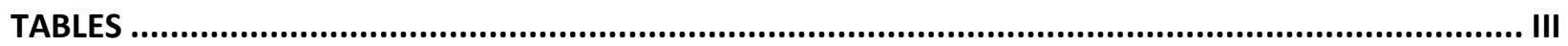

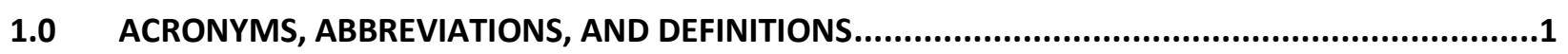

2.0 INTRODUCTION ...................................................................................................................

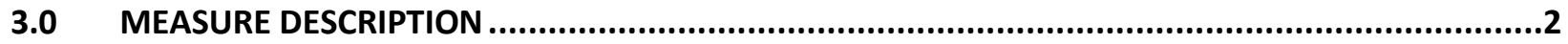

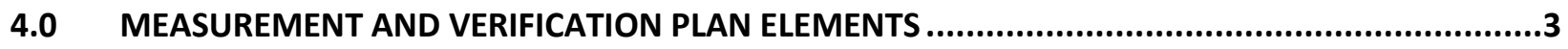

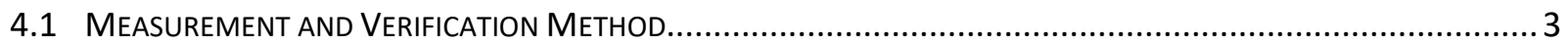

4.2 Measure Description And MeASUREMENT Boundary .................................................................

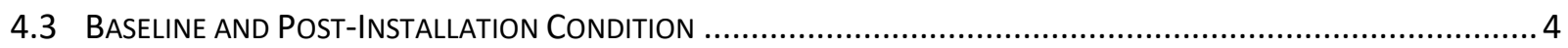

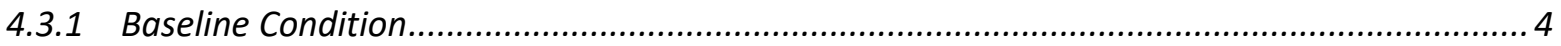

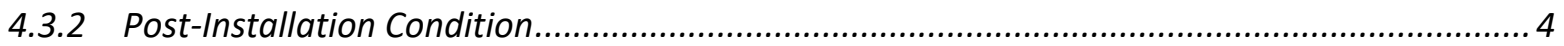

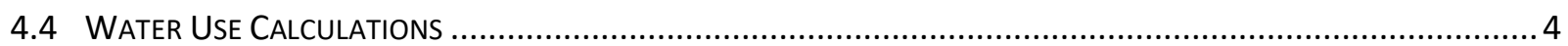

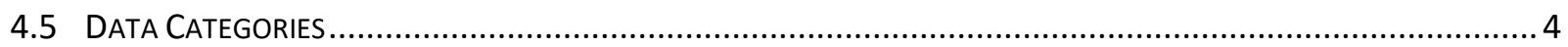

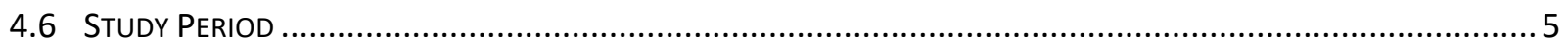

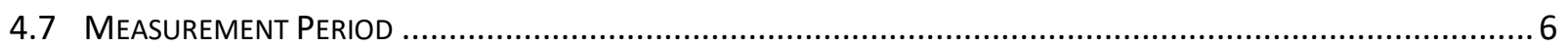

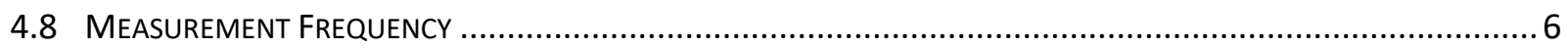

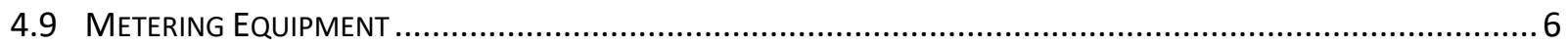

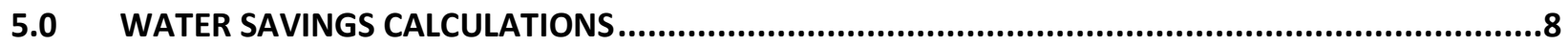

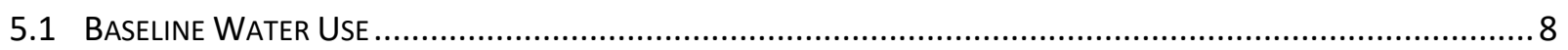

5.1.1 Baseline Water Use Determination........................................................................... 8

5.1.2 Baseline Normalization ....................................................................................... 9

5.2 Post-InStALlation Water Use Determination ......................................................................... 9

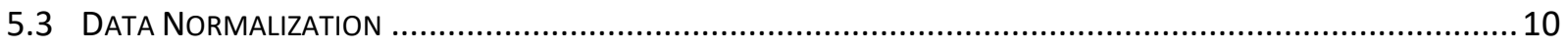

5.4 OTHER CONSIDERATIONS ................................................................................................... 12

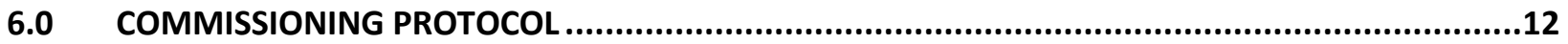




\section{Figures}

Figure A 1. Weather Underground Local Weather Database............................................................1

Figure A 2. National Weather Service Wet Bulb Calculator..................................................................

\section{Tables}

Table 1. Sample Normalization of Cooling Tower Water Use.............................................................. 12

Table A 1. Sample Weather Data Outputs, Weather Underground Local Weather Database..................A.2 


\title{
1.0 Acronyms, Abbreviations, and Definitions
}

\author{
Commissioning \\ The process whereby the measure improvements made to the equipment and/or the control \\ system have been verified to comply with the approved plan, and visually inspected and \\ evaluated for proper operation. \\ Cycles of concentration Term that describes the mass flow relationship between the volume of makeup water and the \\ volume of blowdown water. Sometimes also referred as concentration ratio, this technical \\ term correlates to the effective use of water in a cooling tower system. \\ ESCO \\ Energy Service Company (performance contractor) \\ HVAC \\ heating, ventilation, and air conditioning technology \\ IPMVP \\ International Performance Measurement and Verification Protocol \\ IWMI \\ International Water Management Institute \\ KPI \\ key performance indicator \\ M\&V \\ measurement and verification \\ Measurement boundary \\ The specific cooling towers that are impacted by the WCM and monitored for water savings. \\ Measurement frequency \\ The number of measurements that will be collected over the measurement period to \\ determine water-use savings. \\ Measurement period \\ The time frame water use is monitored, defined by the cooling season. \\ NOAA \\ National Oceanic and Atmospheric Administration \\ Study period \\ The total time frame that water use will be monitored per the contractual arrangement for the \\ baseline and post-installation periods. \\ WCM \\ water conservation measure \\ WESCO \\ Water Efficiency Service Company (performance contractor)
}




\subsection{Introduction}

This measurement and verification (M\&V) protocol provides procedures for energy service companies (ESCOs) and water efficiency service companies (WESCOs) to determine water savings resulting from water conservation measures (WCMs) in energy performance contracts associated with cooling tower efficiency projects. The water savings are determined by comparing the baseline water use to the water use after the WCM has been implemented. This protocol outlines the basic structure of the M\&V plan, and details the procedures to use to determine water savings. It is vital that the customer reviews the M\&V plan thoroughly and agrees to the procedures used by the ESCO or WESCO to collect data and measure water savings.

The procedures presented in this protocol are performance based. The ESCOs and WESCOs are required to measure the amount of water savings directly and do not have to prove the effectiveness of the measure itself. This protocol does not cover other cost streams such as operation and maintenance or energy costs.

\subsection{Measure Description}

This protocol specifies M\&V requirements for WCMs associated with improving the efficiency of cooling tower systems. Cooling tower systems include all components that provide comfort cooling by rejecting heat to the atmosphere through the evaporative process. For the sake of this document, cooling tower systems include open recirculating evaporative coolers, closed-circuit coolers, fluid coolers, and evaporative condensers. System components include piping infrastructure, valves, pumps, heat exchangers, the cooling tower structure, and cooling tower controls. The WCMs covered by this M\&V protocol include, but are not limited to, the following.

\section{Cooling Tower System Efficiency Improvements}

The objective of this measure is to optimize cooling tower efficiency by ensuring that all mechanical components are working properly, and by maximizing the operating cycles of concentration. However, water quality must be a consideration to ensure asset reliability and proper operation of the cooling equipment according to the manufacturer specifications. The water efficiency of the cooling tower is based on minimizing the discharge while not exceeding the saturation limits or corrosive characteristics of the dissolved minerals in the makeup water, with consideration of the operating $\mathrm{pH}$ and system temperatures. This WCM category can include minimizing the expected losses from the system, reducing or eliminating unnecessary losses, and inspecting and repairing system components that are not functioning properly. This includes, but is not limited to, broken or missing drift eliminators, broken or malfunctioning level controls, and broken or malfunctioning distribution decks in the tower.

\section{Conductivity Controls Upgrades}

Conductivity controllers manage the cycles of concentration in the tower system. This measure includes installing controllers that continuously measure the conductivity of the recirculating water and maintain the tower system blowdown to a programmed setpoint. ${ }^{1}$ These controllers can also control liquid chemical treatment based on pulse input from a water meter, in conjunction with blowdown, or based on a timer.

\footnotetext{
${ }^{1}$ Conductivity is an indirect measurement of the dissolved mineral content in the water.
} 


\section{Advanced Control Platforms}

Advanced control platforms are available with multiple sensors that monitor and control system conductivity, chemical treatment levels, $\mathrm{pH}$, corrosion rates, and holding time index. These systems continuously ensure that cooling tower systems operate at optimal cycles of concentration and maintain the desired chemical residuals, while monitoring other critical system parameters such as $\mathrm{pH}$, corrosion rates, holding time index and indirect measurement of biological activity.

\subsection{Measurement and Verification Plan Elements}

The ESCO or WESCO in a performance contract is required to develop a plan that specifies how the M\&V will be performed. This section provides the basic structure of the $M \& V$ plan.

\subsection{Measurement and Verification Method}

The International Performance Measurement and Verification Protocol (IPMVP) has four options (A, B, C, and $D$ ) that can be used to verify the savings of measures. For cooling tower efficiency measures, the recommended IPMVP option to verify water savings is Option B, "Retrofit Isolation." 2

The objective of Option B is to verify performance by measuring the system usage, which increases the accuracy of the verified savings. The retrofit isolation method uses real-time field measurements of the cooling tower system to verify the savings, whereby short-term or continuous measurements are taken throughout the study period.

The cooling tower makeup water flow is the key parameter that is required to be measured using Option $B$, as this must be equal to all the expected or unexpected losses of water from the system.

The IPMVP's Option A, "Partially Measured Retrofit Isolation," allows some stipulated savings. This is a less desirable method because it does not accurately measure the full impact of the measure. Option $C$ ("Whole Building") and Option D ("Calibrated Simulation") are not appropriate M\&V methods for cooling tower efficiency projects because they assess usage at the building level rather than the system level.

This section provides information on the main elements of data collection that should be included in the $M \& V$ plan when using the Option B M\&V method.

\subsection{Measure Description and Measurement Boundary}

The M\&V plan should describe the specific WCMs and the intended results. Additionally, the plan should clearly define the measurement boundary. The measurement boundary defines the specific cooling tower system that will be impacted by the WCM and be monitored for water savings.

\footnotetext{
${ }^{2}$ Option B is the recommended measurement protocol. An alternate acceptable engineering estimate method, however, is provided in section 5.1.1 for the baseline determination.
} 


\subsection{Baseline and Post-Installation Condition}

The M\&V plan should provide a detailed description of the baseline and post-installation conditions that includes information related to the cooling tower system, operating schedule, and the condition of the system before and after the WCM is implemented.

\subsubsection{Baseline Condition}

The plan should include information relevant to the baseline conditions that is collected during the inspection of the cooling tower system, and describe the state of the system components prior to implementation of the WCM. This includes items such as (but not limited to): pipe connections, valves, pumps, tower structure, tower fill, distribution deck, drift eliminators, basin level controls, cooling tower fans, fan and pump drives, heat exchangers, and sources of leaks and losses.

The plan should detail the baseline cycles of concentration and the existing means of controlling cycles of concentration. The plan also should include the operating schedule, and specific changes made to the operating schedule during the baseline year that impact the baseline water use.

The description of the baseline condition of the operating parameters can include, among other things, freeze protection schedules or free cooling schedules in which the tower system supplies condenser water to a plate and frame heat exchanger rather than to a chiller system.

\subsubsection{Post-Installation Condition}

Similarly, the M\&V plan should specify the condition of the cooling tower system that will be achieved through the study period per the commissioning plan (see Section 6.0). This should include information on the cooling tower system components and schedules.

\subsection{Water Use Calculations}

The M\&V plan should include the procedures used to determine the baseline water use and postinstallation water use, which are used to calculate the water savings and to properly normalize the data, if required. Section 5.0 of this protocol provides detailed procedures on the calculation methods. The procedures should be described in detail and reviewed and approved by the customer.

\subsection{Data Categories}

The M\&V plan should specify the distinct categories of data that will be gathered and the methods used to gather the data. It is important for the customer to review and approve the type of data that will be used to determine water-use savings. The following describes the type of data that can be collected.

\section{- Continuous measurement using a dedicated meter}

Volume of water logged by the metering system over the measurement period. Continuous meters can be installed on the cooling tower makeup water supply and the blowdown line. Specify the interval at which the volumetric water use will be logged. If multiple meters are in place that measure water use in the measurement boundary, make 
sure that all meters are included. Data should be gathered monthly, which is required in the normalization process (see Section 5.3).

- Short-term measurement using a temporary meter

Temporary, non-intrusive meters such as ultrasonic meters can be installed to measure system water use for a specified period. The plan should include an agreed upon duration for the temporary metering to be performed to establish typical operating conditions and typical system water consumption.

- Weather data

Average monthly wet bulb temperature data will be used to normalize water use. Average monthly temperature, relative humidity, and barometric pressure can be used to calculate average monthly wet bulb temperature (see Appendix A for methodology to determine wet bulb temperatures).

- Chiller demand

Chiller energy use will be used in conjunction with gallons used by the cooling tower as the key performance indicator (KPI) and should be tracked in terms of ton-hours of cooling demand.

\subsection{Study Period}

The study period covers the total time frame that water use will be monitored per the contractual arrangement for the baseline and post-installation periods. The study period should follow the established $M \& V$ requirements of the State Performance Contracting Program. ${ }^{3}$

The plan should define the baseline period. The baseline study period should be a minimum of one full cooling season, but preferably an average of multiple cooling seasons. ${ }^{4}$ Using an average of multiple years for the baseline study period is preferable because it helps minimize anomalies in water use caused by

Preferable: Baseline study period is an average of multiple cooling seasons

Acceptable: Baseline study period is a minimum of one full cooling season weather patterns or operation changes such as scheduling issues or systemmaintenance problems.

The plan also should define the study period for the post-installation water-use measurement. For example, in the state of Colorado, ESCOs and WESCOs are required

\footnotetext{
${ }^{3}$ See, for example, the State of Colorado's M\&V guidelines for energy savings performance contracts. Nexant. 2008. Measurement and Verification (M\&V) Guidelines for Energy Saving Performance Contracts in State of Colorado Facilities. Boulder, CO. June.

${ }^{4}$ Multiple cooling seasons should encompass three or more years of data.
} 
by statute to provide a written cost savings guarantee for the first three years of the contract period. ${ }^{5} \mathrm{At}$ the agency's discretion, the savings guarantee can be extended beyond the legislatively required period. At the end of each performance year, the ESCO or WESCO is required to submit an annual M\&V report to demonstrate that the savings has occurred.

\subsection{Measurement Period}

The M\&V plan should specify the measurement period, which defines the cooling season. For Colorado, the typical cooling season runs from the middle of May through the end of September. ${ }^{6}$

\subsection{Measurement Frequency}

Measurement frequency is the number of measurements that will be collected over the measurement period to determine water-use savings. To properly normalize the data, water-use data should be collected monthly.

- Water use with a dedicated meter

Water-use data should be collected from the dedicated meter at least monthly, and capture the full measurement period.

- Water use with a temporary meter.

Water-use data can alternately be collected from a temporary meter if a dedicated meter is not installed on the tower system. Data should be collected monthly, and preferably capture the full measurement period. If data collection cannot be accomplished for the full measurement period, then it should be done for an agreed-upon duration that includes the full range of operating conditions - from low cooling demand to peak design cooling demand.

\subsection{Metering Equipment}

The M\&V plan should specify the metering equipment that will be used to measure water use, which should be dedicated meters that monitor only the cooling tower system within the measurement boundary. An existing dedicated meter can be used to determine the baseline water use, which could be customer owned or provided by the water utility.

It is important that the meters used to determine the water use are calibrated and installed correctly. Uncalibrated meters can under-record or over-record water use and therefore can underestimate or overestimate the water use. The ESCO or WESCO should provide the method used to calibrate the meters and provide a calibration certificate to the customer, which should follow the established M\&V

\footnotetext{
${ }^{5}$ Colorado Energy Performance Contracting Office. Colorado Statutes Regarding Energy Performance Contracts for State Government. Title 24 Government - State: Principal Departments: Article 30 Department of Personnel State Administrative Support Services, Part 20 Utility Cost-Savings Measures.

${ }^{6}$ This is based on historical cooling degree days for Denver from 1948 through 2013 from the Western Regional

Climate Center. Accessed at www.wrcc.dri.edu/cgi-bin/cliMONtcdd.pl?co2220.
} 
requirements of the State Performance Contracting Program. If there are potential metering inaccuracies, the ESCO or WESCO should follow any established dispute-resolution steps identified in the State Performance Contracting Program relevant to this issue. Similarly, meters installed incorrectly will give erroneous readings. Therefore, meters must be installed correctly, according to manufacturer specifications, in a location that is easily accessible. Where appropriate meter location in not readily accessible, a remote data transfer system should be installed to provide meter read data to a readily accessible location.

For post-installation water-use measurement, the $M \& V$ plan should provide detailed information on the metering equipment, including the manufacturer, model number, and quantity being installed as part of the measure. The $M \& V$ plan also should provide the metering equipment's installation procedure that includes the length of straight pipe required. The following meter information should be provided in the M\&V plan.

- Volumetric resolution (e.g., within 0.1 gallons)

- Accuracy range at specified ranges of flow rates and sensitivity ${ }^{7}$

- Flow range

- Durability of construction to protect against high pressure and corrosion (e.g., plastic versus brass)

- Water-quality requirements (e.g., filtered versus unfiltered water)

- $\quad$ Line size

- Minimum and maximum operating pressure

- Calibration method and frequency to ensure post-installation water use is accurately determined

The M\&V plan also should provide the type of data-management system that will log water use. The following data management options should also be considered when selecting an appropriate metering system.

- Data logging capability that allows for collection of volumetric water use over distinct intervals (such as 15-minute or 1-hour intervals)

- Web-enabled interface with secure data-storage options

- Automated software updates that patch programming issues

- Capability to interface with other building-automation systems

- Customizable data forms and trending options that allow for short- and long-term graphing of data to evaluate operational issues

\footnotetext{
${ }^{7}$ Sensitivity is a measurement of minimum flow rate required for the meter to record accurate water use. There is a large variance on sensitivity depending on type of meter and size of meter.
} 


\subsection{Water Savings Calculations}

This section provides the procedures that are used to calculate water savings. The general water savings equation is:

Water Use Savings $=($ Baseline Water Use - Post Installation Water Use $) \pm$ Adjustments

Where:

Baseline Water Use = Cooling tower water use of the system prior to WCM implementation Post Installation Water Use $=$ Cooling tower water use after implementation of WCM

Adjustments $=$ Factor applied to normalize water use when appropriate

\subsection{Baseline Water Use}

This section describes methods to determine the baseline water use and the required normalization of the baseline.

\subsubsection{Baseline Water Use Determination}

The following options can be used to estimate baseline water use, and are listed in order of accuracy.

1. Continuous measurement using

a dedicated meter(s). If the existing cooling tower system has a flow meter on the tower makeup that monitors water use over the measurement period for the measurement boundary, then metered data should be Preferable: Continuous measurement using dedicated meters

Acceptable: Short-term measurement using temporary meters during typical operating conditions

Engineering estimate using other parameters collected to determine the baseline water use (see Section 4.5).

2. Short-term measurement using a temporary meter(s). If a dedicated meter is not installed on the existing system, then the baseline water use can be determined using a temporary meter on the cooling tower makeup to monitor water use for an agreed-upon period that includes the full range of operating conditions, from low cooling demand to peak design cooling demand. The temporary meter flow measurement must be extrapolated across the full cooling season to determine the baseline water use. This can be done by multiplying the temporary meter measurement by the duration of the total cooling season divided by the amount of time that the temporary meter was installed. ${ }^{8}$ The calculation is represented by the following equation.

\footnotetext{
${ }^{8}$ Make sure to use the same unit of time (days or weeks) for the duration of the total cooling season, and for period that the temporary meter was installed.
} 
Where:

$$
\text { Baseline Water Use }=T M M g \times\left(\frac{C S}{T M t}\right)
$$

$T M M_{G}=$ The temporary meter measurement, measured in gallons

$C S=$ The time duration of the total cooling season, measured in days or weeks

$T M_{T}=$ The temporary metering time, measured in days or weeks

3. Engineering estimate using other parameters. If neither option 1 or 2 is feasible, then the baseline water use can be determined using some combination of available data including but not limited to pump run times, chiller ton hours, weather data, water balance, and cycles of concentration.

Key Performance Indicator (KPI): After using one of these three methods to establish baseline water use in gallons, it is recommended this be correlated to chiller system energy use. The key performance indicator should be gallons of water used by the cooling tower per ton-hour of chiller cooling demand expressed as gallons/ton-hour.

\subsubsection{Baseline Normalization}

If the study period for the baseline water use is an average of multiple cooling seasons, then normalization of the cooling tower water use is not necessary. If the study period only encompasses one cooling season, however, then the baseline water use should be normalized against historical wet bulb temperatures using the procedure described in section 5.3.

\subsection{Post-Installation Water Use Determination}

As part of the requirements of using the IPMVP Option B M\&V method, a meter is required to measure the post-installation water use over the measurement period.

Continuous measurement using a dedicated meter(s) is the method that meets the requirements of IPMVP Option B because it accurately measures water use over the full measurement period. Therefore, in-line meters should be connected to a centralized control system or a data logger to continuously record water-use data over the measurement period within the measurement boundary.

Key Performance Indicator (KPI): Once the post-installation baseline water use is determined, it should be correlated to chiller system energy use in a manner similar to the protocol used in the baseline determination. The key performance indicator should be gallons of water used by the cooling tower per ton-hour of chiller cooling demand expressed as gallons/ton-hour.

Water Discharge of Water Softeners: Where water softener systems are used to pre-treat the makeup water as part of the overall WCMs, the water supply to the water softener should be measured by a meter. The discharge of the water softener should be included to determine overall water-savings calculations of 
the WCM. If pre-existing water softeners are not dedicated solely for supply water to the cooling towers, then calculating the discharge water to determine net water savings is not required.

\section{Post-Installation Normalization}

The post-installation water use should be normalized against historical wet bulb temperature conditions using the procedure described below in Section 5.3.

\subsection{Data Normalization}

As described in sections 5.1.2 and 5.2 cooling tower water use should be normalized to account for weather variations and adjust the current water use to historical weather patterns.

The cooling tower's water use and heat rejection process of evaporation is governed by the physical and thermodynamic properties of gas and vapor mixtures. This process is dependent on more than just temperature. It relies on the interrelationship of ambient air temperature, relative humidity, and barometric pressure, which are graphically depicted by the psychrometric chart for water. A key measurement in this interrelationship is wet bulb temperature. In simple terms, wet bulb temperature is the lowest temperature that can be achieved by evaporative cooling. ${ }^{9}$

Wet bulb temperature of the air entering the cooling tower is the primary thermal design basis for any evaporative cooling system. For this reason, monthly average wet bulb temperature and historical monthly average wet bulb temperature should be used to normalize cooling tower water use.

Accordingly, follow these steps to normalize the baseline or post-installation water use over the measurement period.

1. Gather the baseline or post-installation water use for each month from metered data collected during the study period, as described in Section 5.1.

2. Determine the average monthly wet bulb temperature for the measurement period using average temperature, average relative humidity, and average barometric pressure for a weather station near the location of the cooling tower. These measurements are available for numerous weather stations at Weather Underground. ${ }^{10}$ These variables then can be entered into a simple online calculator produced by the National Weather Service to determine the average monthly wet bulb temperature. ${ }^{11}$ See 6.0Appendix A for wet bulb determination method.

\footnotetext{
${ }^{9}$ For an expanded discussion on wet bulb temperature, see www.engineeringtoolbox.com/dry-wet-bulb-dewpoint-air-d 682.html.

${ }^{10}$ Available at www.wunderground.com/.

${ }^{11}$ This calculator is available at www.weather.gov/epz/wxcalc rh.
} 
3. Look up the average historical monthly wet bulb temperatures for a weather station near the location of the cooling tower. ${ }^{12}$ The Western Regional Climate Center has data from the mid1990s to 2011 listed by state for multiple weather stations. ${ }^{13}$

4. Determine the monthly ratio of average current wet bulb temperature to the average historical wet bulb temperature during the study period, represented by:

$$
\begin{aligned}
& \text { Monthly Wet Bulb Temperature Ratio } \\
& \qquad \begin{array}{l}
\text { (Historic Monthly Wet Bulb Temperature } \\
\div \text { Current Monthly Wet Bulb Temperature) }
\end{array}
\end{aligned}
$$

5. Normalize each month's water use by multiplying the metered water use by the monthly wet bulb temperature ratio. Then sum all the monthly values to determine the baseline or postinstallation total water use, represented in:

$$
\sum_{n=1}^{n} \text { (Monthly Metered Water Use } \times \text { Monthly Wet Bulb Temperature Ratio) }
$$

Table 1 below provides an example of this normalization method. This example depicts a cooling tower system near the Denver International Airport for a hypothetical study period of May through September of 2016. The water use was 247,000 gallons, as measured by the metering system. The average monthly wet bulb temperature during the study period was slightly higher than the historical values, and the resulting normalized water use is 233,168 gallons.

\footnotetext{
${ }^{12}$ Although ideally this would be the same weather station used in Step 2, the list of weather stations on the Western Regional Climate Center website is not comprehensive. If the same weather station cannot be used for the average historical monthly wet bulb temperature, then use the location nearest the cooling tower or use a weather station with similar climate characteristics.

${ }^{13}$ Available at www.wrcc.dri.edu/htmlfiles/westcomp.wb.html.
} 
Table 1. Sample Normalization of Cooling Tower Water Use

\begin{tabular}{|c|c|c|c|c|c|c|c|c|}
\hline 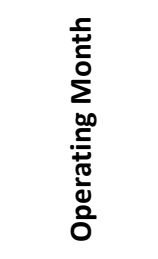 & 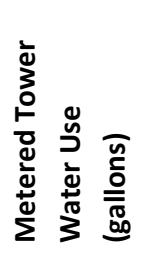 & 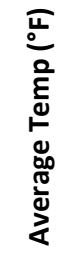 & 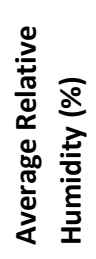 & 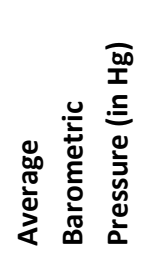 & 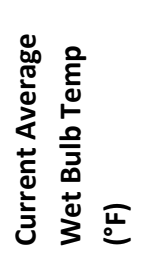 & 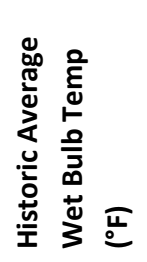 & 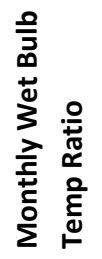 & 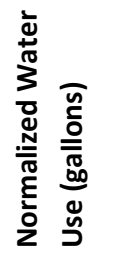 \\
\hline May & 23,000 & 54.6 & 59.7 & 29.9 & 47.7 & 46.7 & 0.98 & 22,518 \\
\hline June & 58,000 & 71.0 & 52.5 & 29.9 & 60.1 & 53.9 & 0.90 & 52,017 \\
\hline July & 76,000 & 76.5 & 45.9 & 29.9 & 62.8 & 59.2 & 0.94 & 71,643 \\
\hline August & 61,000 & 71.5 & 46.9 & 29.9 & 59.0 & 58.1 & 0.98 & 60,069 \\
\hline September & 29,000 & 66.3 & 45.2 & 29.9 & 54.4 & 50.5 & 0.93 & 26,921 \\
\hline Total & 247,000 & & & & & & & 233,168 \\
\hline
\end{tabular}

\subsection{Other Considerations}

The M\&V plan should state any potential issue that could significantly impact water use. If there are potential issues that can significantly impact water use, then the ESCO or WESCO should follow the established dispute-resolution steps identified in the State Performance Contracting Program, which should be reviewed and agreed upon between the ESCO or WESCO, and the customer. Such issues can include (among other things):

- Changes to cooling tower control settings, such as building operators and maintenance crews modifying controller setpoints;

- Mechanical issues, such as failed valves, level controllers, or drives that control pumps and fans;

- Undetected leaks that are not repaired quickly;

- Vendor adjustments made by chemical suppliers;

- Seasonal and intermittent water-quality variances of raw water supply to the cooling towers; and

- Training program for on-site system operators and third-party maintenance contractors regarding WCM changes to the system, proper operating control settings, and warning signs of potential system failure.

The annual M\&V report should provide a detailed description of any significant issue that was experienced, the subsequent impact on water use, and adjustments made to the savings estimate as a result of the issues.

\subsection{Commissioning Protocol}

Commissioning is an important step to ensure the WCM achieves the guaranteed savings. Commissioning is the process whereby the WCM improvements made to the cooling tower equipment and control system have been verified to comply with the approved plan and visually inspected and evaluated for proper operation. Additionally, commissioning verifies that the correct operating schedule has been 
implemented for current cooling needs, and that the building operations and maintenance staff has been trained to properly operate it.

Commissioning ensures that system components are functioning optimally per the measure's design, and checks system performance. ${ }^{14} \mathrm{~A}$ commissioning plan should be established that outlines the specific steps that will be performed. Critical components of the commissioning plan include the following.

- Qualified inspector. A commissioning agent should have the training and competencies to perform the required steps, including electrical, mechanical, and plumbing certifications associated with heating, ventilation, and air conditioning (HVAC) equipment installation and operation. This can include the inspection and verification of a professional engineer.

- Equipment. The plan should detail the type of equipment necessary to perform the commissioning steps.

- Inspection frequency. The plan should provide the time frame of the commissioning inspection, which should be done during and after implementation of the WCM. It might be necessary to recommission the system within the study period to ensure that the system is operating optimally.

- Training. The plan also should specify the training that is required to operate any new equipment installed as part of the WCM.

- Inspections and tests. The plan should specify the types of inspections and tests that will be performed to gauge the performance of the system, which can include (among other things):

o Controller programming. Ensure that the controller has been properly programmed to meet the specific operating parameters of the cooling tower system. This can include, but is not limited to, conductivity setpoint to maintain blowdown control, and pulse input from water meters to control chemical feed, system volume, $\mathrm{pH}$, and to target active chemical treatment levels (if the control platform has real-time capabilities).

o Sensor calibration. Ensure that all sensors monitoring and controlling any parameter are calibrated and working properly.

o System tests. Conduct tests to ensure that the system meets the specifications of the design, including: ${ }^{15}$

- Verification that equipment matches design plans;

\footnotetext{
${ }^{14}$ For an overview of commissioning guidelines and recommendations for cooling tower systems, refer to www.watco-group.co/images/pdf/Commissioning\%20of\%20Cooling\%20Towers.pdf.

${ }^{15}$ Selected items are from the startup and operation checklist, which can be found at www.watcogroup.co/images/pdf/Commissioning\%20of\%20Cooling\%20Towers.pdf.
} 
- Minimum speed ratings of VFDs are coordinated with the requirements of the cooling drivetrain;

- Proper operation of all sensors controlling the fans, pumps, and valves;

- Proper operation of all safety interlocks;

- Loop performance and stability at all operating load conditions;

- Proper operation of freeze protection sequencing; and

- Proper operation of basin heaters, including shutting off when temperatures rise above freezing.

- Minimum performance requirements. The commissioning plan should specify the minimum requirements of the inspection and tests to meet the expected performance of system.

After the commissioning has been performed, the contractor should provide a report that outlines the findings. It is recommended that the customer (or consultants) witness commissioning activities, review the commissioning report, provide comments to the ESCO or WESCO, and have comments resolved to the customer's satisfaction prior to approving the WCM. The report should include the results of all tests performed, state whether the system is functioning per the design, and list necessary corrections. 


\section{Appendix A. Average Wet Bulb Determination}

Average temperature, relative humidity, and barometric pressure are needed to calculate average wet bulb temperature. Weather Underground (www.wunderground.com/) is a good resource to access local weather stations, and includes climate history reports. Figure A 1 illustrates how to use the Weather Underground database to select of the monthly weather history for September 2016 for a weather station at Denver International Airport.

Figure A 1. Weather Underground Local Weather Database

WEATHER
UNDERGROUND

Details of the weather history are available at the bottom of the webpage, including temperature, relative humidity, and barometric pressure (as illustrated in Table A.1 below). 
Table A 1. Sample weather data outputs generated from Weather Underground Local Weather Database, Denver International Airport station, September 2016

\begin{tabular}{|c|c|c|c|c|c|c|c|c|c|c|c|c|c|c|c|c|c|c|c|}
\hline \multirow{2}{*}{$\begin{array}{l}2016 \\
\text { Sep }\end{array}$} & \multicolumn{3}{|c|}{ Temp. $\left({ }^{\circ} \mathrm{F}\right)$} & \multicolumn{3}{|c|}{ Dew Point $\left({ }^{\circ} \mathrm{F}\right)$} & \multicolumn{3}{|c|}{ Humidity (\%) } & \multicolumn{3}{|c|}{ Sea Level Press. (in) } & \multicolumn{3}{|c|}{ Visibility (mi) } & \multicolumn{3}{|c|}{ Wind (mph) } & \multirow{2}{*}{$\begin{array}{l}\text { Precip. (in) } \\
\text { sum }\end{array}$} \\
\hline & high & avg & low & high & avg & low & high & avg & low & high & avg & low & high & avg & low & high & avg & high & \\
\hline 1 & 87 & 71 & 54 & 55 & 53 & 49 & 100 & 64 & 27 & 30.25 & 30.03 & 29.87 & 10 & 8 & 0 & 26 & 11 & 33 & 0.00 \\
\hline 2 & 84 & 73 & 62 & 56 & 50 & 43 & 78 & 51 & 24 & 29.92 & 29.84 & 29.75 & 10 & 10 & 10 & 22 & 10 & 29 & 0.00 \\
\hline 3 & 90 & 74 & 58 & 54 & 47 & 37 & 69 & 43 & 17 & 30.01 & 29.76 & 29.68 & 10 & 10 & 10 & 30 & 10 & 36 & 0.00 \\
\hline 4 & 90 & 71 & 51 & 55 & 47 & 37 & 83 & 50 & 17 & 29.84 & 29.67 & 29.52 & 10 & 10 & 7 & 33 & 9 & 51 & 0.02 \\
\hline 5 & 93 & 72 & 50 & 52 & 42 & 27 & 83 & 47 & 10 & 29.74 & 29.66 & 29.57 & 10 & 10 & 10 & 22 & 9 & 32 & 0.00 \\
\hline 6 & 87 & 73 & 59 & 58 & 54 & 45 & 84 & 53 & 22 & 30.08 & 29.87 & 29.68 & 10 & 10 & 10 & 32 & 10 & 39 & 0.00 \\
\hline 7 & 88 & 70 & 52 & 59 & 48 & 29 & 100 & 57 & 13 & 30.09 & 29.93 & 29.79 & 10 & 6 & 0 & 17 & 7 & 24 & 0.01 \\
\hline 8 & 89 & 69 & 49 & 50 & 35 & 20 & 68 & 38 & 8 & 29.94 & 29.82 & 29.71 & 10 & 10 & 10 & 17 & 7 & 22 & 0.00 \\
\hline 8 & 75 & 60 & 44 & 49 & 37 & 31 & 64 & 46 & 27 & 30.26 & 30.02 & 29.77 & 10 & 10 & 10 & 29 & 11 & 36 & 0.00 \\
\hline 10 & 83 & 60 & 37 & 40 & 33 & 26 & 76 & 45 & 14 & 30.30 & 30.13 & 29.96 & 10 & 10 & 10 & 16 & 11 & 26 & 0.00 \\
\hline 11 & 90 & 72 & 53 & 39 & 24 & 15 & 51 & 29 & 7 & 29.96 & 29.83 & 29.70 & 10 & 10 & 10 & 20 & 9 & 26 & 0.00 \\
\hline 12 & 74 & 63 & 52 & 48 & 38 & 31 & 77 & 50 & 23 & 30.07 & 29.87 & 29.68 & 10 & 10 & 7 & 22 & 12 & 27 & 0.18 \\
\hline 13 & 68 & 58 & 48 & 48 & 46 & 45 & 89 & 69 & 48 & 30.23 & 30.10 & 30.01 & 10 & 10 & 10 & 24 & 14 & 29 & $T$ \\
\hline 14 & 84 & 65 & 46 & 51 & 45 & 39 & 93 & 58 & 22 & 30.12 & 29.96 & 29.80 & 10 & 10 & 9 & 28 & 7 & 34 & $T$ \\
\hline 15 & 78 & 64 & 50 & 49 & 44 & 36 & 83 & 54 & 25 & 30.13 & 29.94 & 29.83 & 10 & 10 & 10 & 26 & 8 & 33 & 0.00 \\
\hline 16 & 73 & 56 & 39 & 44 & 37 & 32 & 76 & 51 & 25 & 30.23 & 30.05 & 29.96 & 10 & 10 & 7 & 23 & 8 & 28 & 0.07 \\
\hline 17 & 78 & 64 & 50 & 43 & 35 & 28 & 82 & 41 & 8 & 30.05 & 29.97 & 29.87 & 10 & 10 & 10 & 15 & 11 & 17 & 0.00 \\
\hline 18 & 88 & 70 & 52 & 33 & 28 & 22 & 38 & 26 & 13 & 30.07 & 29.88 & 29.82 & 10 & 10 & 10 & 18 & 9 & 23 & 0.00 \\
\hline 18 & 90 & 75 & 60 & 36 & 29 & 23 & 34 & 22 & 9 & 30.16 & 29.94 & 29.88 & 10 & 10 & 10 & 25 & 12 & 31 & 0.00 \\
\hline 20 & 90 & 75 & 60 & 34 & 29 & 24 & 36 & 23 & 9 & 29.97 & 29.89 & 29.83 & 10 & 10 & 10 & 22 & 6 & 26 & 0.00 \\
\hline 21 & 84 & 71 & 57 & 44 & 36 & 29 & 55 & 35 & 14 & 29.86 & 29.82 & 29.79 & 10 & 10 & 10 & 28 & 10 & 32 & 0.00 \\
\hline 22 & 76 & 63 & 49 & 54 & 50 & 43 & 100 & 73 & 46 & 30.08 & 29.89 & 29.71 & 10 & 7 & 0 & 18 & 9 & 22 & 0.00 \\
\hline 23 & 88 & 71 & 53 & 53 & 39 & 21 & 89 & 50 & 10 & 29.76 & 29.61 & 29.45 & 10 & 9 & 6 & 37 & 16 & 48 & 0.00 \\
\hline 24 & 71 & 55 & 38 & 38 & 28 & 20 & 85 & 50 & 15 & 30.16 & 29.91 & 29.72 & 10 & 10 & 10 & 28 & 11 & 34 & 0.00 \\
\hline 25 & 68 & 54 & 39 & 32 & 30 & 27 & 70 & 47 & 24 & 30.38 & 30.30 & 30.19 & 10 & 10 & 10 & 22 & 8 & 28 & 0.00 \\
\hline 26 & 76 & 59 & 42 & 32 & 29 & 28 & 62 & 40 & 18 & 30.32 & 30.23 & 30.15 & 10 & 10 & 8 & 14 & 7 & 17 & 0.00 \\
\hline 27 & 83 & 65 & 46 & 33 & 27 & 20 & 58 & 34 & 10 & 30.13 & 30.04 & 29.94 & 10 & 10 & 10 & 13 & 7 & 16 & 0.00 \\
\hline 28 & 82 & 66 & 49 & 36 & 30 & 26 & 42 & 28 & 14 & 30.18 & 30.12 & 30.02 & 10 & 10 & 10 & 16 & 10 & 25 & 0.00 \\
\hline 29 & 87 & 67 & 47 & 40 & 36 & 31 & 56 & 35 & 13 & 30.22 & 30.12 & 29.98 & 10 & 10 & 10 & 23 & 9 & 29 & 0.00 \\
\hline 30 & 74 & 63 & 52 & 47 & 42 & 38 & 62 & 48 & 33 & 30.08 & 30.02 & 29.97 & 10 & 10 & 10 & 21 & 10 & 24 & 0.00 \\
\hline
\end{tabular}

The National Weather Service has an online calculator that can be used to determine wet bulb temperature using ambient air temperature, relative humidity, and barometric pressure, as shown in Figure $\mathrm{A} 2$ below. ${ }^{16}$

${ }^{16}$ The calculator is available at www.weather.gov/epz/wxcalc rh. 
Figure A 2. National Weather Service Wet Bulb Calculator

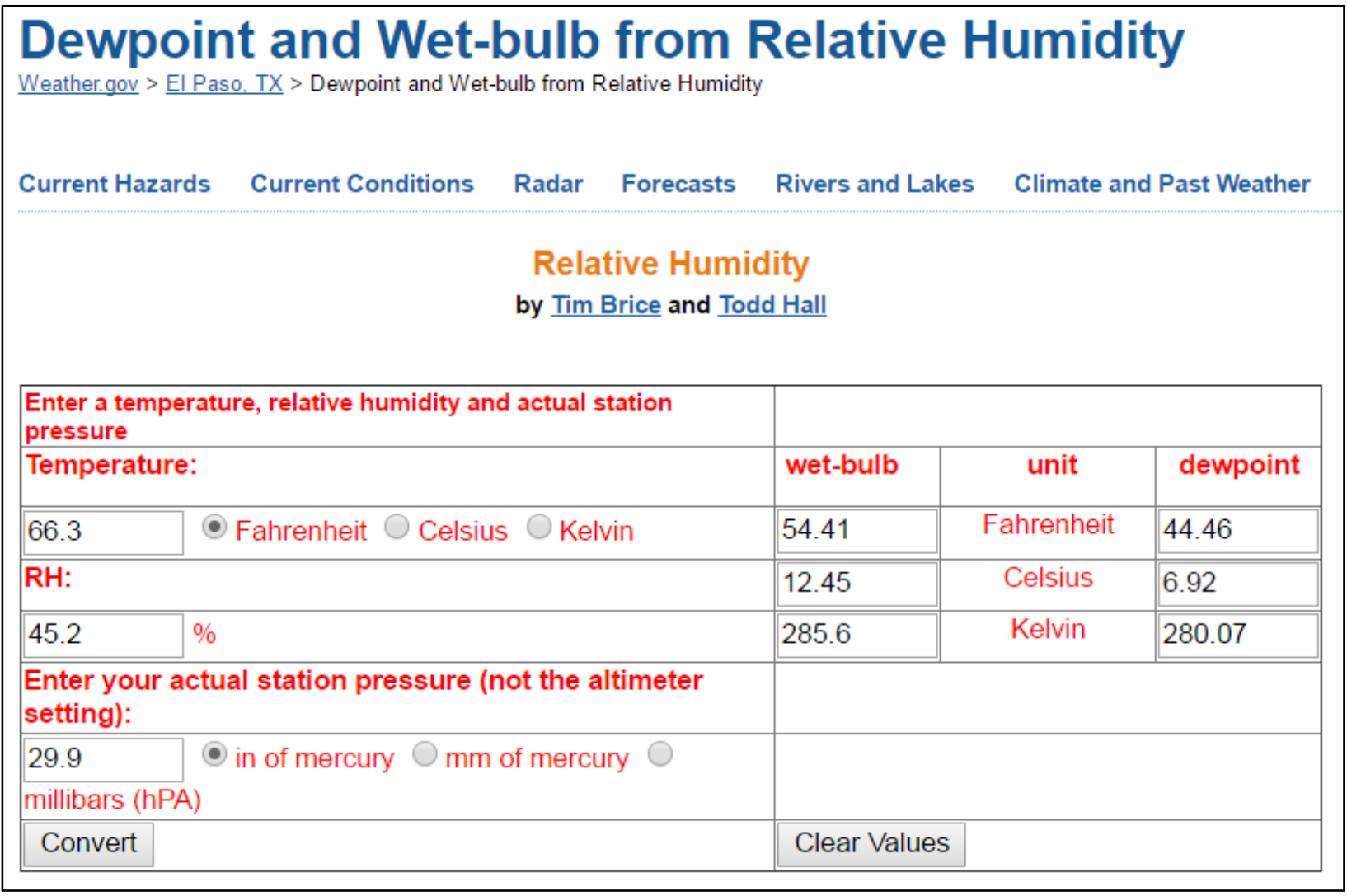

